\title{
Experimental studies of the air conditioning system efficiency in the cab of "TORUM 785" combine harvester
}

\author{
Yury Babenkov ${ }^{1}$, Anatoly Ozersky ${ }^{1}$, Victor Romanov ${ }^{1}$, Galina Galka ${ }^{1, *}$, and Maksim Moro- \\ zov $^{2}$
}

${ }^{1}$ Don State Technical University, sq. Gagarina, 1, 344003 Rostov-on-Don, Russia

${ }^{2}$ PJSC Rostselmash, 344010 Rostov-on-Don, Russia

\begin{abstract}
The article presents the results of field tests and experimental studies of the efficiency of the climatic air conditioning system (ACS) in the cab of a combine harvester "TORUM 785". The studies were carried out according to the Russian methods recommended for use in field tests of tractors and self-propelled vehicles intended for agricultural work in the southern regions of Russia. In the course of the research, a sufficiently high efficiency of the climatic SCR of the cabin of the "TORUM 785" combine harvester was shown under various operating conditions. It is shown that the created climatic SCRs are not inferior to foreign models developed by such companies as John Deere, Claas and New Holland.
\end{abstract}

\section{Introduction}

To ensure comfortable working conditions for drivers of agricultural combines and other vehicles, climatic air conditioning systems (ACS) are currently being created for driver cabs. These systems must operate reliably and efficiently in a variety of operating conditions while meeting the requirements of modern standards. These requirements are fulfilled at the plant of PJSC Rostselmash during the design, creation and testing of climatic SCR of these combines. Experimental research is widely used at all stages of production and testing of technical objects. With the help of experimental data obtained in the course of field tests, the physical and mathematical models of the objects under study are confirmed and refined.

Currently, research by a number of authors has established the insufficient efficiency of existing ACS vehicles [1-5]. The efficiency of ACS is considered here from the point of view of the minimum costs of consumed energy as the most energy-consuming systems installed in transport [6-10]. A number of researchers also note that the existing ACS of combines, based on modern microprocessor technology, do not provide the required accuracy of maintaining the comfortable parameters of heat and humidity treatment of outdoor air under sharp changes in operating conditions, as well as weather conditions [11-15].

\footnotetext{
${ }^{*}$ Corresponding author: ozersckij.ai@yandex.ru
} 
A necessary condition for the development and improvement of modern combines is the creation of effective all-season climatic ACS for their cabins. As is known, the main parameters of the air in the cab of the combine are its cleanliness, absence of gas pollution, temperature, humidity, and also the speed of its movement [1-2].

Comfortable values of the specified air parameters in the cabins of agricultural combine harvesters differ depending on the conditions of their operation. In connection with this, the Institute of Labor and Occupational Diseases of the Academy of Medical Sciences of the Russian Federation for the drivers of these combines performing the appropriate work, it is recommended to maintain comfortable values of air temperature in the combine cab: in summer time $20 \ldots 22^{\circ} \mathrm{C}$ (at a relative humidity of $25 \ldots 60 \%$ ), in winter time $22 \ldots 25^{\circ} \mathrm{C}$ (at a relative humidity of $40-60 \%$ ). The specified parameters must be maintained at the same (in winter and summer) comfortable air speed values $(0.1 \ldots 0.3 \mathrm{~m} / \mathrm{s})$ in working area of combine cab. Approximately the same values of air parameters are recommended by foreign researchers [6].

\section{Main part. Field tests. Experimental results}

In the course of field tests, the task was set to study the efficiency of grain and forage harvesters created by ACS, which provide comfortable working conditions for drivers under various operating conditions of the harvesters. At the same time, the created climatic systems should not be inferior to foreign competitors, such as John Deere, Claas and New Holland.

To solve this problem, it was necessary to investigate the efficiency of the climatic ACSs created at the specified enterprise of the combines under various, especially difficult conditions of their operation. The object of the study was the ACS of the domestic serial grain harvester "TORUM 785", which is being created at the PJSC Rostselmash plant.

Figure 1 shows the layout of the main elements and units of the climatic ACS of the specified combine.

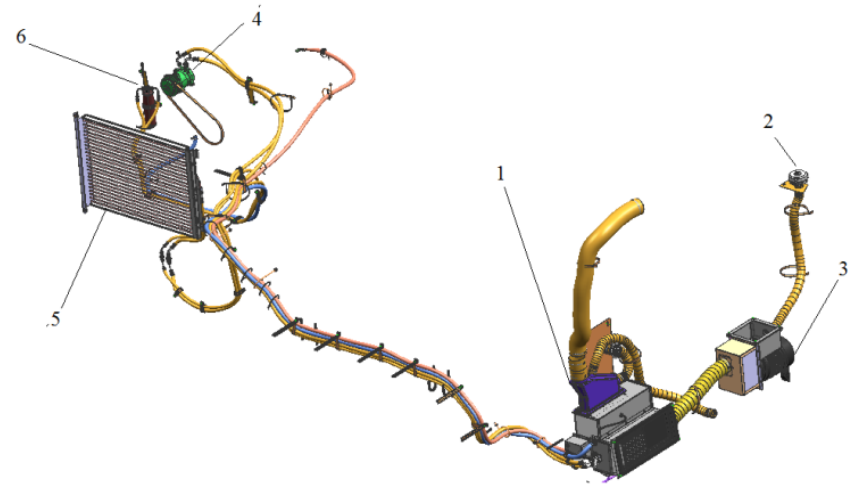

Fig. 1. Layout of elements and units of an effective climatic ACS of the combine "TORUM 785"

Climatic ACS of "TORUM 785" harvester includes an evaporator 1 with a cooling and heating unit and a filter with a connecting hose 2 , a supply ventilation unit 3 , a compressor 4 with an electromagnetic clutch, a condenser 5 with connecting hoses and a receiver 6 .

The harvester engine with the help of a belt drive and an electromagnetic clutch drives the compressor 4, which compresses the gaseous freon and feeds it into the condenser. High temperatures and pressures are generated in the condenser. This is because the compressor used here is a positive displacement machine for compressing and discharging gas. This machine feeds gaseous freon into the channel, the movement through which is limited by the small diameter of the adjustable opening of the thermostatic valve, which partially blocks the 
channel and thus creates a powerful hydraulic resistance to the movement of freon. Therefore, the pressure and temperature of the moving compressible gaseous freon increase. In the condenser, gaseous freon condenses at constant pressure and turns into a liquid with high temperature and pressure. The heat of condensation is dissipated in the environment. The intensity of heat exchange between the condenser and the environment is provided by a fan. After condensation, liquid freon, having high pressure and temperature, is throttled, i.e. expands without doing useful work, coming out of the small opening of the thermostatic valve. As a result of this expansion, the pressure and temperature of the liquid freon sharply decrease. In this case, liquid freon begins to boil at a relatively low temperature and turns into steam of low pressure and temperature. Thus, the thermostatic valve divides the freon path into two channels: a channel with a constant high pressure and a channel with a constant low pressure. The main process associated with air cooling in the working area of the combine cabin takes place in the evaporator. Here the air supplied to the evaporator is cooled using a vane blower. The power of the climate system used in the combines for air cooling is $5.6 \mathrm{~kW}$, the refrigerant is R-134a. The unit is located under the hood of the combine. Here the evaporator is integrated into the heating system. The intensity of heat exchange between the evaporator and the surrounding air is provided by the fan. In this case, the air passing through the evaporator is cooled and forced into the cabin.

Condenser type - tubular-plate $(\mathrm{Cu}-\mathrm{Al})$ with heating capacity $6.5 \mathrm{~kW}$. The condenser is designed to cool the refrigerant by removing heat to the environment. Evaporating-heating unit is a tubular-plate heat exchanger, block expansion valve, centrifugal fan and plastic covers. Heat exchanger cooling capacity $-5,6 \mathrm{~kW}$. Heat exchanger heating capacity $-5,5 \mathrm{~kW}$. Air consumption $-620 \mathrm{~m}^{3} / \mathrm{h}$. The evaporative heating unit draws in air from the environment or recirculated air from the cabin and delivers cooled or heated air to the cabin using a centrifugal fan.

Figure 2 in the $\mathrm{p}-\mathrm{i}$ coordinate system shows the actual cycle of the refrigerating machine of the climate system of the combine, built on the experimental data on the main parameters of the specified machine. In this figure, the temperature values $\mathrm{t},{ }^{\circ} \mathrm{C}$ marked in addition to the main parameters: pressure $\mathrm{p}, \mathrm{Pa}$ and enthalpy $\mathrm{i}, \mathrm{J} /(\mathrm{kgK})$. So, the temperature values are marked on the boundary line separating the different regions of the aggregate states of freon. Tests have shown that, as a result of pressure losses occurring on the suction and discharge lines, as well as in the compressor valves, the refrigeration cycle, in contrast to the theoretical cycle, is displayed on the diagram in a slightly different way. So, due to pressure losses at the inlet to the compressor (section 7-1), the latter carries out suction at a pressure below the evaporation pressure. Along with this, due to pressure losses at the outlet of the compressor (section 2-3), the latter compresses the gaseous refrigerant to a pressure higher than the condensing pressure. In addition to pressure losses in pipelines and valves, the deviation of the real cycle from the theoretical one is also affected by the loss of heat and pressure during the compression process. Therefore, the process of compression of gaseous freon in the compressor (section 1-2) is not adiabatic, but polytropic.

The indicated losses generally reduce the efficiency of the ACS refrigeration machine of the combine.

A thermostatic expansion valve (TEV) is installed to regulate the supply of refrigerant to the evaporator.

The air conditioning system is controlled here by switching the speeds of rotation of the fan shaft. This uses an electronic thermostat with a temperature sensor located on the control panel. 


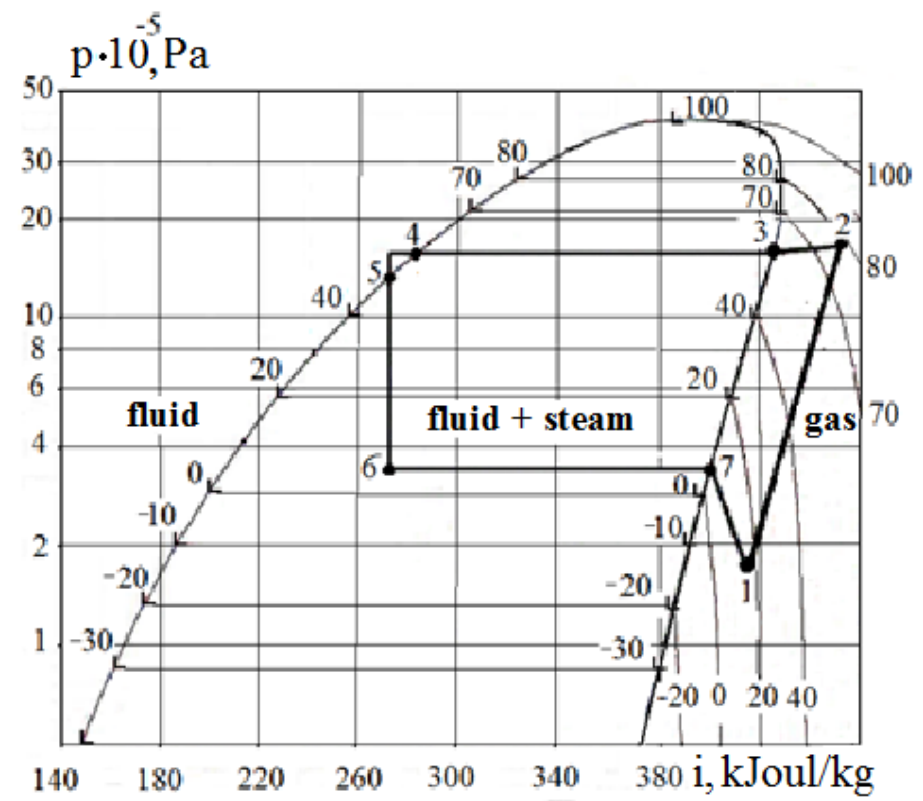

Fig. 2. Cycle of the refrigeration machine of the climate system of the combine "TORUM 785".

The evaporator temperature sensor is installed on the evaporator fins on the air inlet side. It sends a signal to the electronic thermostat to turn off the compressor when the preset air temperature in the evaporator cavity is reached.

A pressure sensor is installed on the receiver and gives a signal to turn off the compressor when the pressure in the system rises above $32 \mathrm{kgf} / \mathrm{cm}^{2}$ and with a decrease in pressure less than $20 \mathrm{kgf} / \mathrm{cm}^{2}$.

The main features of this climate system of the combine are that the evaporating and heating unit is located below the cab. However, this arrangement has both positive and negative effects.

The most important positive effect of the lower arrangement of the unit is the saving of space in the ceiling space of the cab. However, a number of studies and experience of ACS operation have revealed negative factors, such as:

- high heat loss in the lower areas of the cab;

- inconvenience in servicing the filters of the evaporating and heating unit, etc.

Figure 3 shows a schematic diagram of the air conditioning system of the combine cab "TORUM 785". 


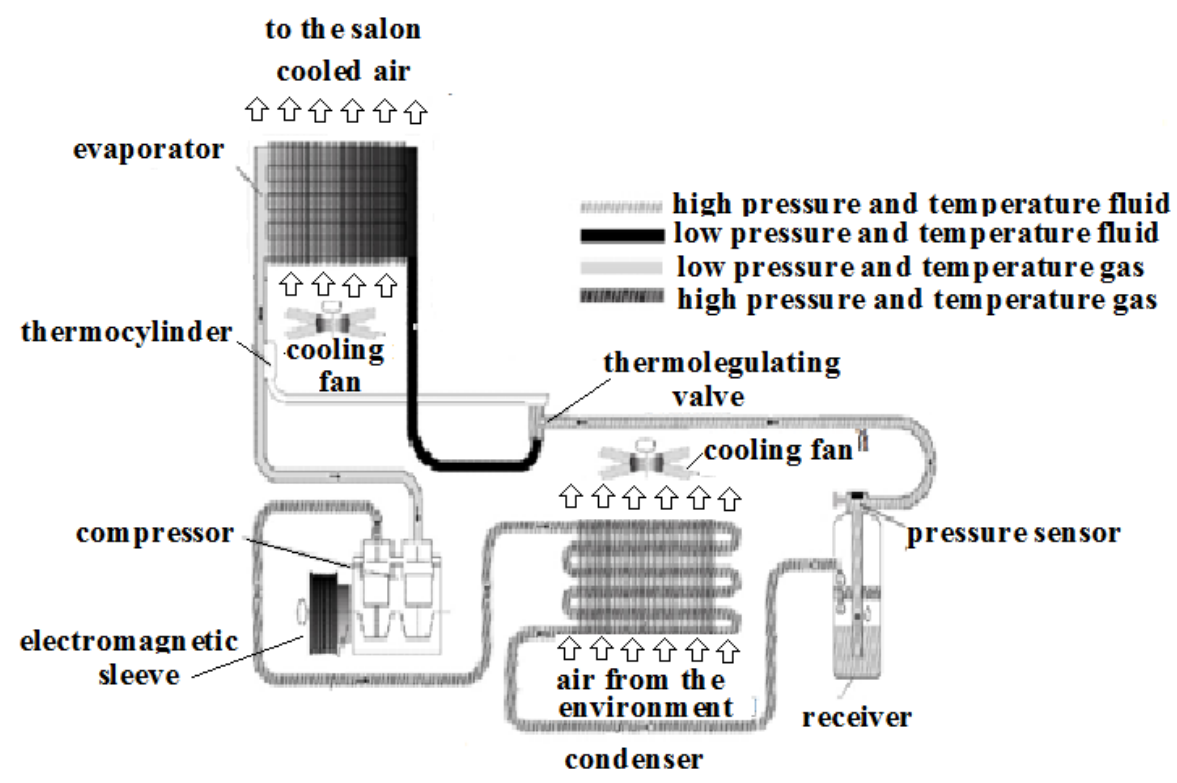

Fig. 3. Schematic diagram of the ACS of the harvester cab "TORUM 785".

In order to answer the question whether the air conditioning system provides comfortable working conditions for the operator, full-scale tests of the climate system were carried out.

Test object:

- climatic ACS combine harvester.

The purpose of the test:

- checking the overpressure in the cab for compliance with the standard conditions;

- checking the efficiency of the climatic ACS harvester.

Measuring instruments:

- digital pressure gauges Testo 512 (№AG49704/712, №AG49703/712);

- thermohygrometers Testo 625 (№62767930, №61153767, №61153761);

- temperature sensors Testo 108 (№ 42611817; № 42611818) with thermocouples type "K"; - anemometer Kimo LV 117 (№ 1P180361514).

Test conditions. The ACS tests of the TORUM 785 combine took place on the territory of Rostselmash LLC on June 28, 2018, the testing time was from 14:30 to 16:30. Test conditions are presented in Table 1.

Table 1. Test conditions 


\begin{tabular}{|c|c|c|c|}
\hline Indicators & \multicolumn{3}{|c|}{ The value of indicators according to test data } \\
\hline Test time & $\begin{array}{c}\text { Clear } \\
\text { weather }\end{array}$ & Test start 14:30 & $\begin{array}{c}\text { End of tests } \\
16: 30\end{array}$ \\
\hline Solar radiation* & $\begin{array}{c}\text { Clear } \\
\text { weather }\end{array}$ & Light cloudiness & Light cloudiness \\
\hline Relative humidity, \% & $\begin{array}{c}\text { Clear } \\
\text { weather }\end{array}$ & $76.3-76.5$ & $85.8-86.0$ \\
\hline $\begin{array}{c}\text { Ambient dry bulb tempera- } \\
\text { ture, }{ }^{\circ} \mathrm{C}\end{array}$ & $\begin{array}{c}\text { Not less thar } \\
+32\end{array}$ & $38.5-39.5$ & $39.7-40.3$ \\
\hline $\begin{array}{c}\text { Ambient air temperature wet } \\
\text { bulb, }{ }^{\circ} \mathrm{C}\end{array}$ & $\begin{array}{c}\text { Not less than } \\
+25\end{array}$ & $20.2-20.5$ & $20.7-21.0$ \\
\hline $\begin{array}{c}\text { The speed of movement of air } \\
\text { entering the machine in the } \\
\text { direction from front to back, } \\
\text { m/s }\end{array}$ & $\begin{array}{c}\text { Not more } \\
\text { than } 5\end{array}$ & $1.1-3.1$ & $0.9-3.3$ \\
\hline \multicolumn{2}{|c|}{$*$ Requirements for test conditions according to the standard. } \\
\hline \multicolumn{4}{|c|}{} \\
\hline
\end{tabular}

The combine also measured the excess pressure in the cab. Before the start of measurements, all vents of the ventilation system in the cab were fully open; the harvester engine was started and set at rated speed. Overpressure measurements were performed for each of the 3 fan speeds. The measurement results are presented in table 2 .

Table 2. Measurement results

\begin{tabular}{|c|c|c|c|c|}
\hline \multirow{2}{*}{ Indicators } & \multicolumn{3}{|c|}{ Fan operating modes } & Standard requirements \\
\cline { 2 - 4 } & 1 & 2 & 3 & \\
\hline $\begin{array}{c}\text { Excessive pressure in } \\
\text { the cabin, Pa } \\
\text { (test start) }\end{array}$ & 23 & 30 & 45 & $\begin{array}{c}\text { Not less than } 50 \mathrm{~Pa} \text { and } \\
\text { not more than } 200 \mathrm{~Pa}\end{array}$ \\
\hline $\begin{array}{c}\text { Excessive pressure in } \\
\text { the cabin, Pa } \\
\text { (end of tests) }\end{array}$ & 112 & 118 & 125 & \\
\hline
\end{tabular}

According to the measurement results, the overpressure in the cab of the combine harvester "TORUM 785" meets the requirements of the standard at all speeds of the fan shaft.

Measurements of temperature and humidity in the cab during the operation of the air conditioner of the climate system on "TORUM 785" combines were carried out according to the method described in the Russian Standard. Before starting the engine of the combine, the initial values of temperature and humidity in the driver's cab were measured. The results of measurements of the initial values are entered in the first lines of tables 3 and 4 (zero time stamp).

During the experiment, the harvester was installed in such a way that the sun was in front of the right, at an angle $25 \ldots 30^{\circ}$ from the longitudinal axis of the combine. Before the start of the tests, all vents of the ventilation system in the cab were fully open and oriented in such a way as to provide maximum airflow to the operator's body. Then the engine is started, the air conditioner knob is set to the maximum cooling position, and the fan speed controller into position 3. After that, the parameters were measured at 6 points of the working area of the cabin (Figure 4) with the air conditioner of the climate system running at a time interval of 4 minutes. The tests were carried out until the moment when the air temperature in the cabin at the points under study did not change by more than $0.5^{\circ} \mathrm{C}$ within 15 minutes. The measurement results are shown in Tables 3 and 4. Based on the test results, graphs of changes 
in temperature and air humidity in the working area of the cabin were built (see Figures 5, 6).

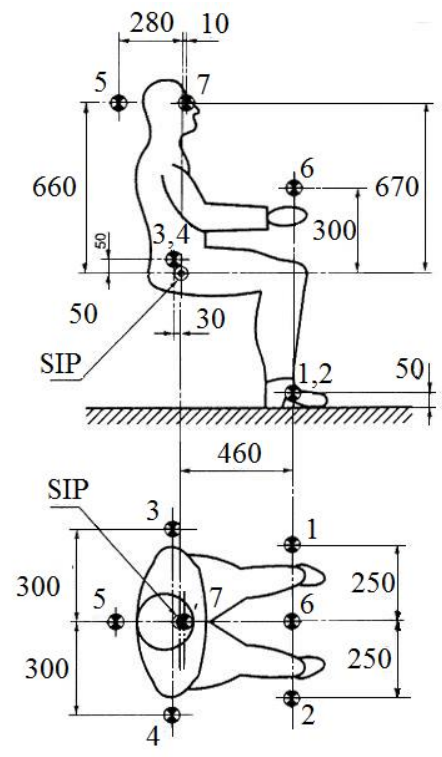

Fig. 4. Location of measurement points

The test results of the air conditioner of the climate system are presented in Table 3, as well as in Figures 5 and 6.

Table 3. Results of the air conditioner of the climate system

\begin{tabular}{|c|c|c|c|c|c|c|c|c|c|}
\hline \multirow{2}{*}{$\begin{array}{l}\dot{\Xi} \\
\dot{\Xi} \\
\dot{\Xi} \\
\dot{\Xi}\end{array}$} & \multicolumn{6}{|c|}{$\begin{array}{c}\text { Cabin air temperature of "TORUM 785" by dry } \\
\text { bulb, }{ }^{\circ} \mathrm{C}\end{array}$} & 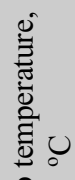 & \multirow{2}{*}{ 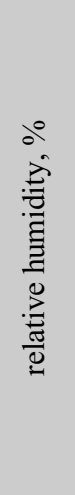 } & \multirow{2}{*}{ 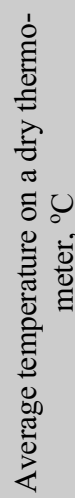 } \\
\hline & $\overrightarrow{.}$ & 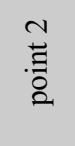 & 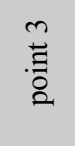 & 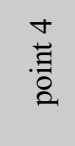 & 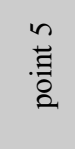 & $\begin{array}{l}0 \\
>\end{array}$ & 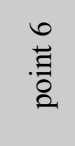 & & \\
\hline 0 & 40.9 & 41.4 & 40.1 & 40.1 & 40.1 & 40.1 & 24.4 & 25.7 & 40.4 \\
\hline 4 & 32.6 & 33.3 & 32.2 & 32.6 & 32.9 & 32.2 & 18 & 24.6 & 32.6 \\
\hline 8 & 29.3 & 29.8 & 29.2 & 29.3 & 30.1 & 29.6 & 16.7 & 27.3 & 29.5 \\
\hline 12 & 27.4 & 28.6 & 27.4 & 27.8 & 28.8 & 28 & 15.9 & 27.7 & 28 \\
\hline 16 & 26.1 & 27.5 & 26.6 & 26.7 & 27.5 & 27 & 15.2 & 28.5 & 26.9 \\
\hline 20 & 25.5 & 26.3 & 25.5 & 25.9 & 26.5 & 26.1 & 14.7 & 29 & 26 \\
\hline 24 & 24.3 & 25.4 & 24.4 & 25.2 & 26 & 25.6 & 14.5 & 29.1 & 25.1 \\
\hline 28 & 24.5 & 25.6 & 24.3 & 24.5 & 25.5 & 25.2 & 14.1 & 28.7 & 24.9 \\
\hline 32 & 25.5 & 26.5 & 24.4 & 24.5 & 25.4 & 24.7 & 13.8 & 29.6 & 25.2 \\
\hline 36 & 23.6 & 24.5 & 24 & 24.4 & 25.1 & 24.8 & 13.9 & 29 & 24.4 \\
\hline
\end{tabular}




\begin{tabular}{|c|c|c|c|c|c|c|c|c|c|}
40 & 24.2 & 26.2 & 23.6 & 24.4 & 25.1 & 24.9 & 14 & 30 & 24.7 \\
\hline 44 & 24 & 25.6 & 24 & 24.2 & 25.2 & 24.7 & 13.9 & 29.3 & 24.6 \\
\hline 48 & 23.6 & 24.4 & 23.9 & 24.3 & 25.1 & 24.7 & 14 & 29.8 & 24.3 \\
\hline 52 & 23 & 25 & 23.5 & 24.2 & 25.1 & 24.7 & 13.9 & 29.4 & 24.2 \\
\hline 56 & 24.5 & 25.3 & 23.8 & 24.4 & 25.1 & 24.8 & 14 & 30.4 & 24.6 \\
\hline 60 & 23.7 & 25.3 & 24.1 & 24.5 & 25.2 & 24.9 & 14.3 & 30.1 & 24.6 \\
\hline
\end{tabular}

So, Figure 5 shows the results of a study of the efficiency of the ACS during field tests. This figure shows changes over time $\tau$, min. of basic parameters: temperature $t,{ }^{\circ} \mathrm{C}$ and relative humidity $\varphi, \%$. Here:

- curve 1 - change in ambient air temperature;

- curve 2 - change in the relative humidity $\varphi$ of the air in the working area of the cabin;

- curve 3 - change in the average air temperature at the workplace at point 6 ;

- curve 4 - change in air temperature at the workplace according to "wet bulb" at point 6 .

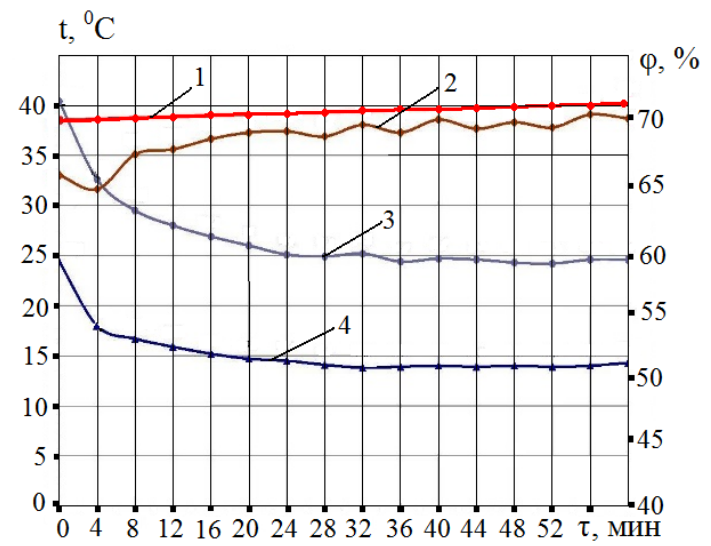

Fig. 5. Experimental time dependences of temperature and relative humidity of air in the combine cab.

Figure 6 also shows the results of a study of the efficiency of the ACS during field tests.

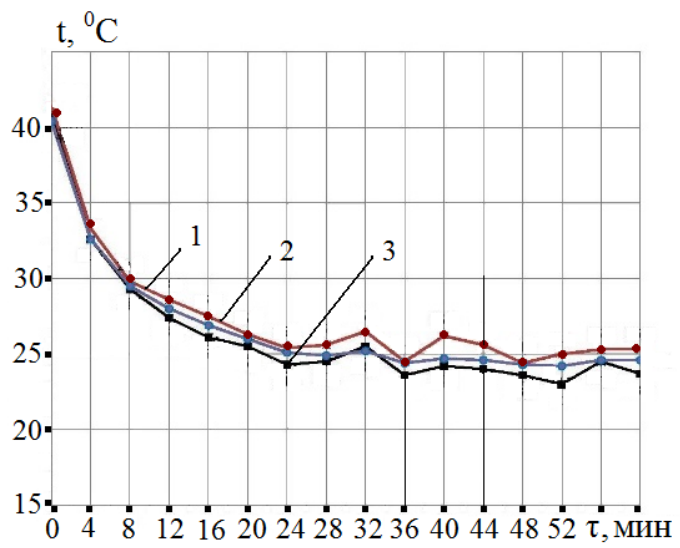

Fig. 6. Experimental time dependence of the air temperature at the workplace in the combine cab. 
This figure shows curves showing changes over time $\tau$, min. temperature $\mathrm{t},{ }^{\circ} \mathrm{C}$ at various points in the working area of the cab (see Figure 4).

Here:

- curve 1 - change in ambient air temperature;

- curve 2 - change in the relative humidity $\varphi$ of the air in the working area of the cabin;

- curve 3 - change in the average air temperature at the workplace at point 6 ;

- curve 4 - change in air temperature at the workplace according to "wet bulb" at point 6 .

According to the results of the tests of the air conditioner of the climate system of the combine "TORUM 785" at 60 minutes (see the graph in Figure 5), the steady-state average air temperature in the cabin was $+24.6{ }^{\circ} \mathrm{C}$ (at ambient temperature $+38,5 \ldots+40,3{ }^{\circ} \mathrm{C}$ ). The maximum difference between the average temperature of the air in the cabin and the environment was $15,7{ }^{\circ} \mathrm{C}$, which corresponds the GOST requirements. According to these requirements, the air conditioner must ensure that the air temperature at the workplace is not lower than $11^{\circ} \mathrm{C}$ (at ambient temperatures over $+38^{\circ} \mathrm{C}$ ). In this case, the maximum temperature difference at the control points of the cabin was $1,6{ }^{\circ} \mathrm{C}$, which also corresponds the requirements of the standard (according to these requirements, the air temperature at the workplace at the control points should not differ by more than $5^{\circ} \mathrm{C}$ ).

\section{Output}

Based on the test results, it can be concluded that the climate system for the combine being created at the PJSC Rostselmash plant "TORUM 785" able to provide comfortable conditions at the operator's workplace under various operating conditions of the combine. At the same time, the requirements of the standard are met. At ambient temperatures above 40 ${ }^{\circ} \mathrm{C}$ comfortable conditions in the cab are provided within the recommended range only 40 minutes after the system is started. This indicates, however, that there is a low level of air exchange in the cab under the specified conditions. To increase the intensity of air exchange in the combine cab and to increase the efficiency of the ACS under these conditions, additional costs of energy supplied from the outside are required.

\section{References}

1. B. Meskhi, Y. Bulygin, V. Maslenskyk, Calculation and choice of climatic system for the cabin of the combine harvester TORUM, State and prospects for the development of the agro-industrial complex: sb. scientific. tr. XII International academic and research conf., 653-657 (Rostov-on-Don: Publishing House DSTU-Print, 2019)

2. B. Meskhi, Y. Bulygin, E. Shchekina, V. Maslensky, Development of elements of the microclimate normalization system in the cabin of the combine harvester TORUM, Safety of man-made and natural systems 2, 2-12 (2019)

3. B. Meskhi, Y. Bulygin, E. Shchekina, V. Maslensky, Elements of the normalization system of microclimate in the cabin of grain mandy combine TORUM, IOP Conference Series: Earth and Environmental Science 403, 12-19 (2019)

4. B. Meskhi, Y. Bulygin, V. Maslensky, I.N. Loskutnikova, Evaluation of the thermal radiation regime of the crane operator's workplace in order to reasonably choose the climatic system of the metallurgical crane cabin, Occupational safety in industry 2, 714 (2021)

5. V. Maslensky, Y. Bulygin, A finite-element analysis of microclimate parameters in the cockpit of a metallurgical crane, Safety of man-made and natural systems 1, 10-20 (2021) 
6. S. Rațiu, I. Laza, V. Alexa, V. Cioată, Practical studies on car air conditioning systems. IOP Conf. Series: Materials Science and Engineering 393, 12-13 (2018)

7. S. F. XU, X. L. YANG, Z. Ying, The Analysis for Energy Consumption of Marine Air Conditioning. System Based on VAV and VWV (2018)

8. Á. Andrade, Á. Restrepo, J. Tibaquirá. A performance analysis of fixed and variable air conditioning at different cooling thermal conditions. Universidad Tecnológica de Pereira, Pereira, Colombia. Contents lists available at ScienceDirect. Energy Reports. Journal Energy Reports 7, 537-545 (2021)

9. D. Nalawade. Smart Air Conditioning Market Share, Forecast Report to 2027.

10. https://www.researchgate.net/publication/348382114 (Last accessed 2021/02/12)

11. J. Santosh, S. Chauhan, R. Kota, A. D'souza, A. Joshi Heat, Exchanger for Hybrid Air Conditioning System. IOSR Journal of Mechanical and Civil Engineering (IOSR-JMCE) e-ISSN: 2278-1684, p-ISSN: 2320-2334 www.iosrjournals.org International Conference on Advances in Engineering. \& Technology - ICAET (2014) (last accessed 2021/02/21)

12. V. Govindaraju, D. Vilathgamuwa, R.Ramanujan. Modelling of a magnetocaloric system for cooling in the kilowatt range. Int. J. Refrig. 43, 143-153 (2014)

13. F. Albertini, C. Bennati, M. Bianchi, L. Branchini, F. Cugini, Preliminary Investigation on a Rotary Magnetocaloric Refrigerator Prototype. Energy Procedia 142, 1288-1293 (2017)

14. S. Qian, Y. Wang, L. Yuan, J. Yu, A heat-driven elastocaloric cooling system. Energy 182, 881-899 (2019)

15. J. Tušek, K. Engelbrecht, N. Pryds, Elastocaloric effect of a Ni-Ti plate to be applied in a regenerator-based cooling device. Sci. Technol. Built Environ. 22, 489-499 (2016)

16. A. Greco, C. Aprea, A. Maiorino, C. Masselli, A review of the state of the art of solidstate caloric cooling processes at room-temperature before. Int. J. Refrig. 106, 66-88 (2019) 